\title{
CST does not evict elongating telomerase but prevents initiation by ssDNA binding
}

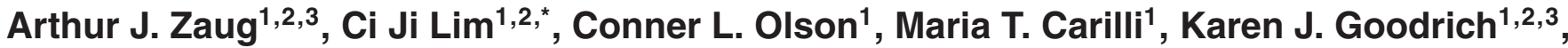 \\ Deborah S. Wuttke ${ }^{\oplus 1,{ }^{*}}$ and Thomas R. $\operatorname{Cech}^{1,2,3,{ }^{*}}$
}

${ }^{1}$ Department of Biochemistry, University of Colorado Boulder, Boulder, CO 80309, USA, ${ }^{2}$ BioFrontiers Institute, University of Colorado Boulder, Boulder, CO 80309, USA and ${ }^{3}$ Howard Hughes Medical Institute, University of Colorado Boulder, Boulder, CO 80309, USA

Received August 25, 2021; Revised September 29, 2021; Editorial Decision September 29, 2021; Accepted October 01,2021

\section{ABSTRACT}

The CST complex (CTC1-STN1-TEN1) has been shown to inhibit telomerase extension of the Gstrand of telomeres and facilitate the switch to $\mathrm{C}$ strand synthesis by DNA polymerase alpha-primase (pol $\alpha$-primase). Recently the structure of human CST was solved by cryo-EM, allowing the design of mutant proteins defective in telomeric ssDNA binding and prompting the reexamination of CST inhibition of telomerase. The previous proposal that human CST inhibits telomerase by sequestration of the DNA primer was tested with a series of DNA-binding mutants of CST and modeled by a competitive binding simulation. The DNA-binding mutants had substantially reduced ability to inhibit telomerase, as predicted from their reduced affinity for telomeric DNA. These results provide strong support for the previous primer sequestration model. We then tested whether addition of CST to an ongoing processive telomerase reaction would terminate DNA extension. Pulse-chase telomerase reactions with addition of either wild-type CST or DNA-binding mutants showed that CST has no detectable ability to terminate ongoing telomerase extension in vitro. The same lack of inhibition was observed with or without pol $\alpha$ primase bound to CST. These results suggest how the switch from telomerase extension to C-strand synthesis may occur.

\section{GRAPHICAL ABSTRACT}

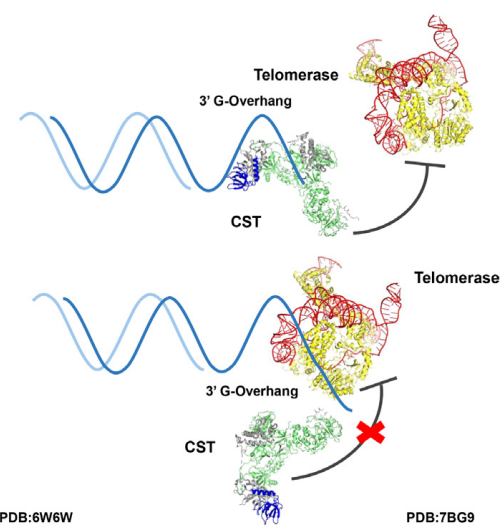

\section{INTRODUCTION}

Telomerase, a ribonucleoprotein enzyme, comprises a template-containing RNA (1), a reverse transcriptase protein (2) and accessory subunits that differ among ciliates, vertebrates, and yeast $(3,4)$. By maintaining chromosomal telomere length, telomerase allows continuous proliferation of stem cells and cancer cells. The last decades have witnessed substantial progress in understanding telomerase's enzymatic mechanism, biogenesis, recruitment to telomeres and 3D structure (5-8). At the same time, research has begun to shed light on the synthesis of the C-rich strand of the telomere (9-14).

Key to the switch from telomeric G-strand synthesis by telomerase to $\mathrm{C}$-strand synthesis by pol $\alpha$-primase is the CST complex, consisting of CTC1, STN1 and TEN1 $(15,16)$. CST binds single-stranded DNA (ssDNA) with some specificity for the telomeric sequence $(15,17,18)$. CST prevents telomerase re-initiation by sequestering the $3^{\prime}$ end

\footnotetext{
*To whom correspondence should be addressed. Tel: +1 303492 8606; Fax: +1 303492 6194; Email: thomas.cech@colorado.edu Correspondence may also be addressed to Ci Ji Lim. Tel: +1 608 265 4690; Email: ciji.lim@wisc.edu

Correspondence may also be addressed to Deborah S. Wuttke. Tel: +1 303492 4576; Email: deborah.wuttke@colorado.edu Present addresses:

Ci Ji Lim, Department of Biochemistry, University of Wisconsin-Madison, Madison, WI 53706, USA. Maria T. Carilli, Program in Biochemistry and Molecular Biophysics, Caltech, Pasadena, CA 91125, USA.
} 
of the telomeric primer (17). It also directly binds pol $\alpha$ primase and acts as a cofactor for stimulation of pol $\alpha$ primase activity (19).

Structures of various domains and subcomplexes of CST were solved by X-ray crystallography in the Skordalakes lab $(20,21)$. The cryo-EM structure then showed how these domains were incorporated into the heterotrimer and revealed a binding site for single-stranded telomeric DNA in the CTC1 subunit (22). Unexpectedly, these heterotrimers can also self-assemble into a 2-MDa decameric supercomplex with an overall double-ring structure (22). Although data support the existence of the decamer in cells, it remains challenging to ascertain which functions (or additional functions) of CST are accomplished by the heterotrimer versus the decamer (22).

In this work, we utilize human CST DNA-binding mutant proteins that maintain assembly of the heterotrimeric complex but have reduced affinity for telomeric DNA. We find that these mutant proteins have reduced ability to inhibit initiation of telomerase extension. Quantitative profiles of telomerase inhibition as a function of added CST were well fit by an exact treatment of competitive primer binding using experimentally validated binding constants. This analysis provides strong support for the primer sequestration model of Chen, Redon and Lingner (17). We then tested whether CST could terminate ongoing extension of telomeric DNA by telomerase, which would provide a powerful mechanism to switch from G-strand synthesis to Cstrand synthesis. However, we show that such termination does not occur to an appreciable extent under multiple conditions in vitro. Together, our data support the model where CST primarily blocks telomerase through primer sequestration, with the switch from telomerase G-strand synthesis to pol $\alpha$-primase $\mathrm{C}$-strand synthesis occurring either passively or facilitated by factors beyond the telomerase holoenzyme, the CST complex, and pol $\alpha$-primase.

\section{MATERIALS AND METHODS}

\section{Reagents}

Other than stated, we purchased chemicals from SigmaAldrich (St. Louis, MO) or Thermo Fisher Scientific (Waltham, MA), DNA modifying enzymes from New England Biolabs (NEB, Ipswich, MA) and DNA oligonucleotides from Integrated DNA Technologies (IDT, Coralville, IA). The 18-nucleotide 3xTEL DNA is 5'TTAGGGTTAGGGTTAGGG-3'. For fluorescence polarization binding assays, 3xTEL was 5' 6-carboxyfluorescein labeled by IDT.

\section{Biological resources}

The pcDNA mammalian expression vector (V79020, Thermo Fisher Scientific) was used to clone cDNAs expressing the human CST subunits. The CTC1 cDNA (MGC: 133331) has a 3xFLAG tag, STN1 cDNA (MGC: 2472) a Myc tag and TEN1 cDNA (MGC: 54300) a HA tag, all three tags residing on the $\mathrm{N}$-termini of the proteins. CTC1 mutagenesis was performed using standard DNA mutagenesis protocol and confirmed by sequencing the gene. HEK239T cells (CRL-1573, ATCC, Manassas, VA) were cultured in DMEM medium supplemented with 2 $\mathrm{mM}$ L-glutamine, $1 \%$ penicillin/streptomycin and $10 \%$ fetal bovine serum.

\section{Expression and purification of proteins in human cultured cells}

The three plasmids encoding the CST subunits were transfected into HEK293T cells at 1:1:1 molar ratio using lipofectamine 2000 (11668019, Thermo Fisher Scientific). The cells were further expanded (typically 3 -fold) for $24 \mathrm{~h}$ after transfection and then harvested. The cell pellets were lysed with CHAPS lysis buffer (10 mM Tris- $\mathrm{HCl} \mathrm{pH} 7.5,1 \mathrm{mM}$ $\mathrm{MgCl}_{2}, 1 \mathrm{mM}$ EGTA, $0.5 \%$ CHAPS, $10 \%$ glycerol, $5 \mathrm{mM}$ $\beta$-mercaptoethanol, $1 \mathrm{mM}$ PMSF) for $45 \mathrm{~min}$ at $4{ }^{\circ} \mathrm{C}$ on a rotator. The lysate was then clarified by centrifugation at $13000 \times \mathrm{g}$ at $4^{\circ} \mathrm{C}$ for $30 \mathrm{~min}$. Anti-FLAG resin (A2220, Sigma-Aldrich) was added to the clarified supernatant and the samples incubated in a rotator for $4 \mathrm{~h}$ (or overnight) at $4{ }^{\circ} \mathrm{C}$. The anti-FLAG resins were washed thrice with wash buffer (20 mM HEPES-NaOH pH 8.0, $150 \mathrm{mM} \mathrm{NaCl}, 2$ $\mathrm{mM} \mathrm{MgCl} 2,0.2 \mathrm{mM}$ EGTA, $0.1 \%$ NP-40, $10 \%$ glycerol, 1 $\mathrm{mM}$ TCEP) before elution using wash buffer supplemented with $0.25 \mathrm{mg} / \mathrm{ml} 3 x$ FLAG peptide (F4799, Sigma-Aldrich). The eluent was then subjected to another round of affinity purification using anti-HA resin (26181, Thermo Fisher Scientific) with similar buffers but 3 XFLAG peptide replaced with HA peptide (A6004, APExBIO, Houston, TX) for elution. Purified CST complexes were verified with SDS-PAGE using a silver staining kit (24612, Thermo Fisher Scientific). For experiments that required pol $\alpha$-primase removal from CST, the $\mathrm{NaCl}$ concentration in the wash and elution buffers was raised from 150 to $300 \mathrm{mM}$.

For the $K_{\mathrm{d}}$ measurements, CST protein concentrations were determined by western blot analysis with anti-CTC1 antibody (see next section) using a serial dilution of the HEK-cell CST preparation and a standard curve obtained by serial dilution of an insect cell-purified CST standard. For the telomerase inhibition experiments, CST concentrations were determined by the same method but with the anti-STN1 antibody. We subsequently found that the antiSTN1 antibody consistently gave a 3 -fold lower protein concentration, possibly because of different post-translational modifications in the HEK cell and insect cell preparations. This difference does not affect the relative $K_{\mathrm{d}}$ values (mutants versus WT) or the relative $\mathrm{IC}_{50}$ values, which are the basis for most conclusions herein. However, it required multiplying the CST concentrations by a factor of 3 when fitting the experimental data to the exact competitive binding expression and when calculating the dependence of $\mathrm{IC}_{50}$ on [DNA], because these calculations involve both $\mathrm{IC}_{50}$ and $K_{\mathrm{d}}$ values.

\section{Western blotting}

The presence of CST and pol $\alpha$-primase subunits in the HEK239T cell-purified CST complexes was analyzed by western blotting. The primary antibodies were anti-FLAG (A8592, Sigma-Aldrich), anti-HA (NB600-362H, Novus 
Biologicals, Centennial, CO), anti-CTC1 (MABE 1103, EMD Millipore, Burlington, MA), anti-STN1 (NBP201006, Novus Biologicals, Centennial, CO), anti-POLA1 (ab31777, Abcam, Cambridge, UK), anti-POLA2 (217781-AP, ProteinTech, Rosemont, IL), anti-PRIM1 (10773-1AP, ProteinTech), and anti-PRIM2 (NBP2-58498, Novus Biologicals). Secondary antibodies used were anti-rabbit (711-035-152, Jackson ImmunoResearch, West Grove, PA) and anti-mouse (715-035-150, Jackson ImmunoResearch). All primary antibodies were diluted 1:1000 for blotting. The dilution for secondary antibodies was performed according to the manufacturer's recommendations.

\section{Electrophoresis mobility shift assay (EMSA)}

The 3xTEL oligo was $5^{\prime}$ radiolabeled with $\left[\gamma-{ }^{32} \mathrm{P}\right] \mathrm{ATP}$ (NEG035C005MC, PerkinElmer) using a standard T4 polynucleotide kinase labeling protocol (M0201L, NEB). Each binding reaction ( $10 \mu \mathrm{l}$ sample volume) contained 500 counts per min (c.p.m.) of radiolabeled 3xTEL in binding buffer (20 mM HEPES-NaOH pH 8.0, $150 \mathrm{mM} \mathrm{NaCl}, 2$ $\mathrm{mM} \mathrm{MgCl} 2,0.2 \mathrm{mM}$ EGTA, $0.1 \%$ NP-40, 10\% glycerol, 1 mM DTT) with or without CST added. The binding reactions were incubated on ice for $2 \mathrm{~h}$ before loading onto a $1 \times$ TBE, 0.7\% SeaKem ${ }^{\circledR}$ LE Agarose (50004, Lonza Group, Basel, Switzerland) agarose gel. Gel electrophoresis was performed in a cold room $\left(4^{\circ} \mathrm{C}\right)$ for $1.5 \mathrm{~h}$ at 6.6 volts $/ \mathrm{cm}$. The gels were dried on Hybond N+ (RPN303B, Cytiva Amersham ${ }^{\top M}$, Little Chalfont, UK) and two pieces of 3MM chromatography paper (3030917, Cytiva Whatman ${ }^{\text {TM }}$ ) at $80^{\circ} \mathrm{C}$ for $1.25 \mathrm{~h}$. They were then exposed to a phosphorimager screen overnight. The screen was imaged with a Typhoon FLA9500 scanner (GE Lifesciences). The fraction of the DNA bound $\theta$ was calculated by dividing the counts from the gel-shifted band(s) over total counts per lane. The apparent dissociation constant, $K_{\mathrm{d} \text {,app. }}$, was then determined from fitting the fraction bound values to the following Hill equation,

$$
\theta=\frac{P^{n}}{P^{n}+K_{\mathrm{d}, \text { app. }}^{n}}
$$

where $P$ is the CST protein concentration and $n$ is the Hill coefficient.

\section{Fluorescent polarization (FP) binding assay}

Each binding reaction ( $20 \mu 1$ sample volume) contained 750 pM of fluorescently labeled 3xTEL oligo in either EMSA binding buffer (for telomerase) or telomerase binding buffer (for CST). Serial dilutions of binding reactions were set up in a 384-well plate (Cat No: 3575, Corning Inc., Corning, NY). Control wells with only binding buffer were also included in each experiment. The binding reactions were incubated for 1.5-2 $\mathrm{h}$ at room temperature in the dark. Fluorescent intensity (parallel and perpendicular polarization) of each reaction were measured using a ClarioStar Plus FP plate reader (BMG Labtech, Ortenberg, Germany) and fluorescent anisotropy values of each protein titration were calculated. $K_{\mathrm{d} \text {,app. }}$ was determined by fitting the anisotropy value $\left(F_{\mathrm{A}}\right)$ to the quadratic equation for single site binding by non-linear least squares fitting,

$$
\begin{aligned}
F_{\mathrm{A}}= & O+\frac{S}{2[\mathrm{~L}]}\left(\left(K_{\mathrm{d}, \text { app. }}+P+[\mathrm{L}]\right)\right. \\
& \left.-\sqrt{\left(K_{\mathrm{d}, \text { app. }}+P+[\mathrm{L}]\right)^{2}-4 P[\mathrm{~L}]}\right)
\end{aligned}
$$

where $O$ is the minimum anisotropy observed, $S$ is the difference between the maximum and minimum anisotropy observed, $P$ is the concentration of protein and $[\mathrm{L}]$ is the concentration of DNA. Averages calculated are the mean values from experiments.

\section{Direct telomerase assay}

Human telomerase expression and purification followed the protocol of Cristofari and Lingner (23). The telomerase extension assay was performed in $50 \mathrm{mM}$ Tris $-\mathrm{HCl} \mathrm{pH} 8.0$, $50 \mathrm{mM} \mathrm{KCl}, 75 \mathrm{mM} \mathrm{NaCl}$ (some brought in with CST and the remainder supplemented), $2 \mathrm{mM} \mathrm{MgCl}, 1 \mathrm{mM}$ spermidine, $5 \mathrm{mM} \beta$-mercaptoethanol, $0.33 \mu \mathrm{M}\left[\alpha{ }^{32} \mathrm{P}\right] \mathrm{dGTP}$ $\left(3000 \mathrm{Ci} \mathrm{mmol}^{-1}\right), 2.9 \mu \mathrm{M}$ cold dGTP, $0.5 \mathrm{mM}$ dATP and $0.5 \mathrm{mM}$ TTP.

For standard experiments, CST, telomerase $(2.0 \mathrm{nM})$, and $3 \times$ TEL oligo ( $10 \mathrm{nM}$ unless indicated otherwise) were incubated at room temperature for $30 \mathrm{~min}$ before $3 \mu \mathrm{l}$ of dNTP mix was added to initiate telomerase extension (final reaction volume of $20 \mu \mathrm{l})$. The samples were incubated at $30^{\circ} \mathrm{C}$ for $1 \mathrm{~h}$ (unless indicated otherwise) before adding $100 \mu \mathrm{l}$ of stop solution (3.6 $\mathrm{M} \mathrm{NH}_{4} \mathrm{Ac}$ containing $20 \mu \mathrm{g}$ glycogen and 3000 c.p.m. of each of three oligonucleotide loading controls, LC1, LC2 and LC3). The samples were ethanol precipitated and then dissolved in $10 \mu 1$ water plus $10 \mu 12 \times$ gel loading buffer $(0.1 \times \mathrm{TBE}, 93 \%$ formamide, $50 \mathrm{mM}$ EDTA, $0.05 \%$ bromophenol blue, and $0.05 \%$ xylene cyanol). $10 \mu 1$ of each sample was loaded on a $10 \%$ acrylamide, $7 \mathrm{M}$ TBEurea sequencing gel (pre-run for $45 \mathrm{~min}$ at $90 \mathrm{~W}$ constant) and electrophoresis was performed at $90 \mathrm{~W}$ constant until the bromophenol blue dye was at the bottom of the gel, about $2 \mathrm{~h}$. The gel was then dried and exposed to a storage phosphor screen before imaging.

For experiments in which CST was added to an ongoing telomerase reaction, telomerase and 3xTEL oligo were preincubated at room temperature for $30 \mathrm{~min}$ before initiating telomerase extension (by adding dNTP mix). CST proteins were then added to the reaction 2 or $10 \mathrm{~min}$ after dNTP addition. For pulse-chase experiments, excess cold dGTP and CST were added to the telomerase reactions immediately after the 10 min time point. Radiolabeled telomerase DNA synthesis products were analyzed by ImageQuant (GE Lifesciences). Telomerase activity was determined by total counts per lane, and processive extension was calculated as counts in high molecular weight products ( $\geq 10$ repeats) divided by total counts per lane. $\mathrm{IC}_{50}$ values were determined by fitting the telomerase activity data to the equation

$$
\text { Fraction activity }=\frac{1}{1+\left(\frac{P}{\mathrm{I}_{50}}\right)}
$$

where $P$ is the CST protein concentration. 


\section{Competitive binding modeling and simulation}

The following exact mathematical equations for calculating fraction of ligand bound to protein, $\theta$, in a competitive binding situation (originally derived by Wang (24) were coded into a python script,

$$
\begin{gathered}
a=K_{\mathrm{d}_{\mathrm{A}}}+K_{\mathrm{d}_{\mathrm{B}}}+[\mathrm{A}]_{0}+\gamma[\mathrm{B}]_{0}-[\mathrm{L}]_{0} \\
b=K_{\mathrm{d}_{\mathrm{B}}}\left([\mathrm{A}]_{0}-[\mathrm{L}]_{0}\right)+K_{\mathrm{d}_{\mathrm{A}}}\left(\gamma[\mathrm{B}]_{0}-[\mathrm{L}]_{0}\right) \\
+K_{\mathrm{d}_{\mathrm{A}}} K_{\mathrm{d}_{\mathrm{B}}} \\
c=-K_{d_{A}} K_{d_{B}}[L]_{0} \\
\theta=\arccos \left(\frac{-2 a^{3}+9 a b-27 c}{2 \sqrt{\left(a^{2}-3 b\right)^{3}}}\right) \\
\frac{[\mathrm{LA}]}{[\mathrm{A}]_{0}}=\frac{\left\{2 \sqrt{\left(a^{2}-3 b\right)} \cos \left(\frac{\theta}{3}\right)-a\right\}}{3 K_{A}+2 \sqrt{\left(a^{2}-3 b\right)} \cos \left(\frac{\theta}{3}\right)-a}
\end{gathered}
$$

The script was designed to accept user input parameters; $K_{\mathrm{d}_{\mathrm{A}}}$ and $K_{\mathrm{d}_{\mathrm{B}}}$, the dissociation constants of the competing binders (Telomerase and CST, respectively) for the ligand (DNA); $[\mathrm{L}]_{0}$, the concentration of ligand; $[A]_{0}$, the concentration of Telomerase; and $[\mathrm{B}]_{0}$, a titrated range of initial concentrations of CST.

The final expression calculated is $\frac{[\mathrm{LA}]}{[\mathrm{A}]_{0}}$, or fraction of telomerase bound to DNA ligand. Normalized fraction bound was then calculated by dividing all values by the value of fraction bound evaluated at $[\mathrm{B}]=0 \mathrm{nM}$ (in the absence of CST). The equation was also adapted from the original version to accept a manipulatable, unitless $\gamma$ factor that represented the percent of active CST. This factor was added as a coefficient to concentration of protein B (CST) before calculating normalized fraction bound of ligand to telomerase.

\section{Fitting of experimental telomerase inhibition data}

Best fit curves were generated for experimental competitive binding data. An array of $100 \gamma$ values ranging linearly from 0.0 to 2.0 and an array of $100 K_{\mathrm{d}_{\mathrm{A}}}$ values ranging linearly from 0.0 to 4.0 were created. For every pair of $\gamma$ and $K_{\mathrm{d}_{\mathrm{A}}}$ values, a python script was used to calculate the Residual Sum of Squares (RSS) between the exact equation's predicted fraction bound and the experimentally determined fraction bound under the same conditions according to the following equation,

$$
R S S_{\gamma, K_{\mathrm{d}_{\mathrm{A}}}}=\sum_{i=n}^{n}\left(y_{i}-f\left(x_{i}\right)\right)^{2}
$$

where $y_{i}$ is the experimentally determined fraction bound, $f\left(x_{i}\right)$ is the exact equation's prediction of fraction bound under $y_{i}$ 's conditions, and $n$ is the total number of experimental data points. The value of $K_{\mathrm{d}_{\mathrm{B}}}$ was set at $2.20 \mathrm{nM}$, the concentration of telomerase at $2.0 \mathrm{nM}$, and DNA concentrations ranged between 5.0, 10.0, 25.0, 50.0, 100.0 and
200.0 nM, corresponding to telomerase-CST inhibition experiments. $10000 \mathrm{RSS}$ values were calculated with a minimum value of 0.499 and maximum value of 28.1. Error space was visualized with a $2 \mathrm{D}$ heat map corresponding to RSS values for each $\gamma, K_{\mathrm{d}_{\mathrm{A}}}$ pair. The darkest color was set to correspond to the minimum RSS value and the brightest color was set to twice of the saturation RSS value.

The pair with the lowest RSS was then used to generate best fit curves and plotted with experimental data. Best fit curves and heat map were generated using the python Matplotlib graphics package (25).

\section{RESULTS}

\section{CST mutant proteins defective in binding ssDNA}

The cryo-EM structure of human CST revealed a binding site for four nucleotides (TAGG) of the TTAGGG telomeric repeat in Oligonucleotide/oligosaccharide Binding Folds (OB folds) F and G of the CTC1 subunit (22). Mutagenesis was performed on groups of amino acids (designated ' $\mathrm{g}$ '), designed to give a substantial reduction in DNA affinity (Figure 1A). A negative control mutant g4.1 switched the charge of two amino acids that are not directly involved in DNA binding. While qualitative DNA binding experiments with some of these mutants have been reported (22), the present studies required quantitative measurements.

The three CST subunits were coexpressed in HEK-293T cells. A double affinity pull-down method relying on a 3xFLAG tag on CTC1 and a HA tag on TEN1 resulted in substantially pure CST complexes (Supplementary Figure S1). The WT and all mutant proteins all assembled stable heterotrimers, as judged by co-IP of the three subunits (Figure 1B). It initially appeared that the protein preparation contained four contaminating polypeptides (Supplementary Figure S1), but mass spectrometry and western blots showed that these were in fact the subunits of pol $\alpha$ primase, known binding partners of CST (26-29) (Figure $1 \mathrm{C})$. Because pol $\alpha$-primase was not overexpressed, these subunits are endogenous.

The CTC1 subunit consistently ran as two bands, both containing the N-terminal 3xFLAG tag and the epitope for the CTC1 antibody. The upper band has a molecular weight consistent with full-length CTC1 (135 kDa), while the lower band X (ca. $114 \mathrm{kDa}$ ) is of unknown origin. Interestingly, mutant g1.1 was bereft of pol $\alpha$-primase and of the faster-migrating CTC1 species, providing a useful tool to test whether these components affect DNA binding. Pol $\alpha$-primase binding appears to be required for nuclear localization of CST (29), but how this could be related to the absence of the smaller CST isoform is unclear.

DNA binding affinity was assessed by both Electrophoretic Mobility Shift Assays (EMSA) and Fluorescence Polarization (FP). Each technique has its advantages, the EMSA allowing detection of a single or multiple bound species, and the FP being more of a true equilibrium technique. For practical reasons, the EMSA was done at $4^{\circ} \mathrm{C}$ and the FP at $22^{\circ} \mathrm{C}$, so one would not expect the apparent dissociation constant ( $K_{\mathrm{d} \text {,app. }}$ ) values to be the same, but the trends seen with the mutants should be consistent between assays. 
A

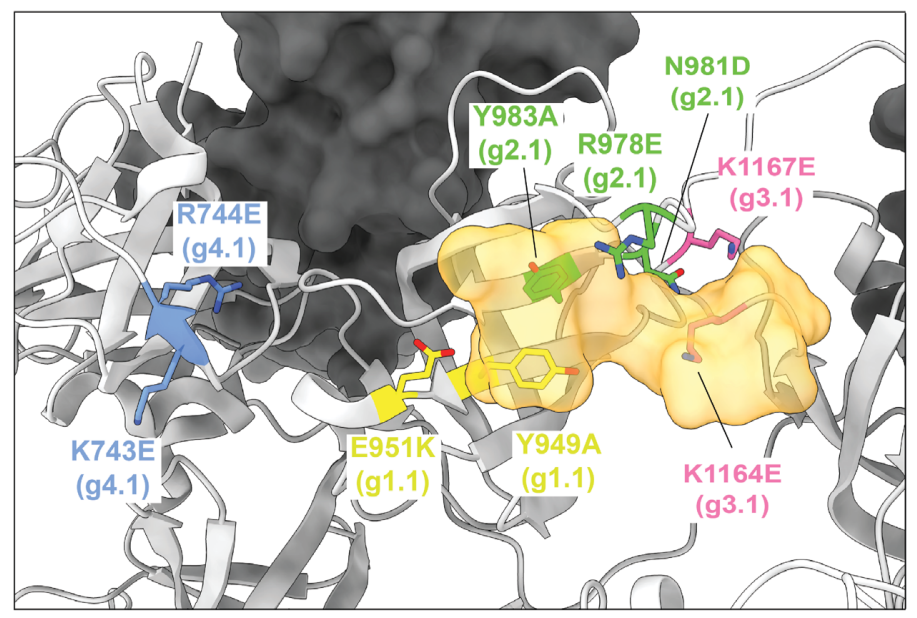

B

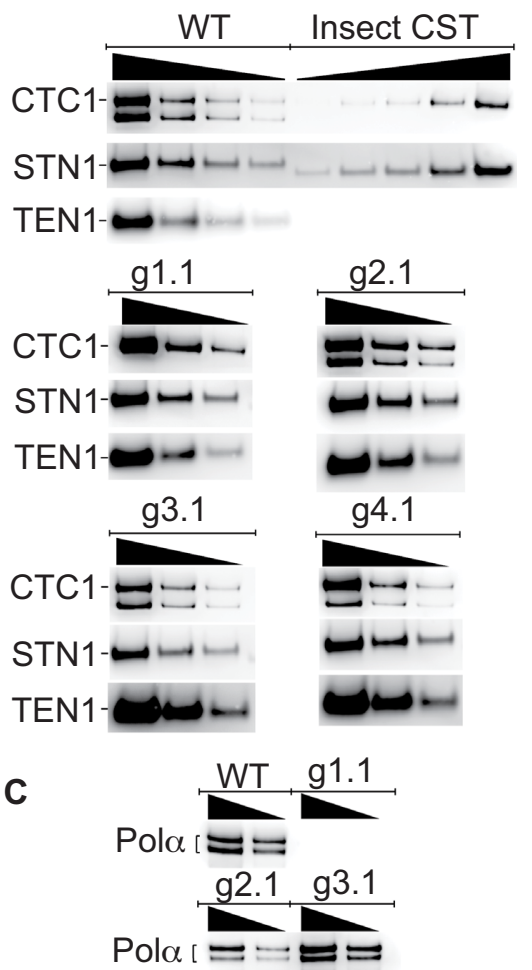

Figure 1. CST DNA-binding mutants maintain subunit assembly and mostly maintain pol $\alpha$-primase binding. (A) Location of mutated amino acids relative to the DNA (half opaque surface representation, orange) in the cryo-EM structure of CST (22). Grey ribbon, CTC1. Dark surface, STN1. (B) All mutants maintain assembly of CTC1, STN1 and TEN1 subunits. Insect cell recombinant CST (shown here on WT CST gel) was always included to allow plotting a standard curve to calculate concentration of HEK cell CST. Lack of reliable anti-TEN1 antibody led us to probe the HA-tagged TEN1 with anti-HA antibody; the insect cell TEN1 lacked this tag, so was not revealed. The lower band of CTC1, of unknown origin, was consistently missing in the g1.1 mutant. (C) WT CST and all mutants except g1.1 co-purify with pol $\alpha$-primase, shown here for the two pol $\alpha$ subunits and in Supplementary Figure S1 for the primase subunits. In panels (B) and (C), wedges indicate successive two-fold dilutions of protein.

Sample EMSA data are shown in Figure 2A. The three mutants designed to be defective in DNA binding bound the 3xTEL DNA probe at much higher protein concentrations than the WT or g4.1 control mutant. Furthermore, the DNA binding-defective mutants all showed at least two DNA-bound complexes on the native agarose gel. The species with the greater retardation had an electrophoretic mobility similar to that of the bound species seen with WT CST and the g4.1 mutant, while the new species ran at an intermediate mobility. It seems unlikely that the intermediate species contains a subcomplex rather than a complete CST heterotrimer, because the three subunits remained associated during immunopurification (Figure 1B) and subcomplexes do not have such high EMSA mobility (30) or structural stability $(30,31)$. In any case, the DNA-binding mutants displayed a $30-50$ fold reduction in affinity to the $3 x$ TEL ssDNA, while the negative control had a $K_{\text {d,app. }}$ similar to that of WT CST (Figure 2B and Table 1). The curve fits gave Hill coefficients of $1.02 \pm 0.18$ ( $n=9$ experiments) for WT CST and $1.03 \pm 0.19(n=14$ experiments $)$ for the DNA binding mutants, indicating that binding was not cooperative.

FP data are plotted in Figure 2C and compiled in Table 1. Consistent with the EMSA data, the DNA-binding mutants showed a large increase in $K_{\mathrm{d} \text {,app., }}$ and the g4.1 negative control had a $K_{\mathrm{d} \text {,app. }}$ similar to that of WT CST. In- terestingly, the reduction in affinity for the DNA-binding mutants observed in the FP assays was greater than in the EMSA experiments, 190-360-fold for FP compared to 1532-fold for EMSA (Table 1). The differences could be explained by the inherent differences of the two assays, with the FP assays being performed at a higher temperature as mentioned above and the FP assays being run at a lower salt concentration to match the telomerase inhibition experiments. Furthermore, the FP assay is better suited than EMSA for measuring binding with weaker binding proteins due to it being a true equilibrium experiment. Overall, though, the trends between the two experiments are consistent.

\section{CST inhibition of telomerase initiation depends on DNA binding}

To compare the ability of various CST complexes to inhibit the initiation of telomerase extension, direct telomerase assays were performed. When telomerase was incubated with the 3xTEL telomeric DNA primer and dNTPs, the 6-nt ladder of extension products characteristic of telomerase was observed, and incorporation of radioactive $\left[\alpha{ }^{32} \mathrm{P}\right] \mathrm{dGTP}$ nucleotides was linear for at least two hours (Figure 3A, B). When WT CST was preincubated for $30 \mathrm{~min}$ with telomerase and the primer, the pattern of extension products was 
A
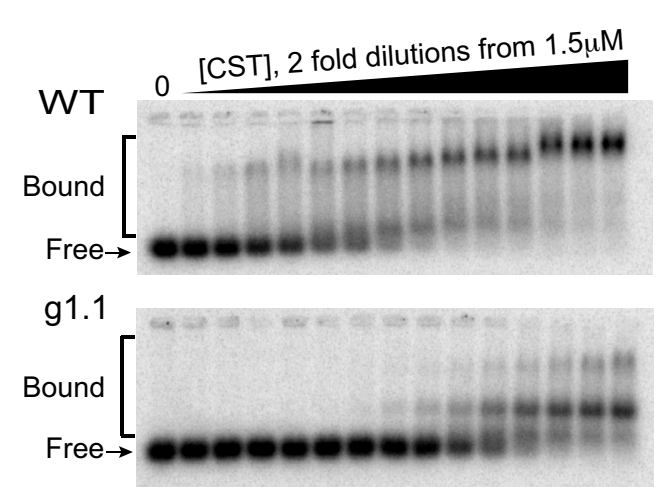

g2.1
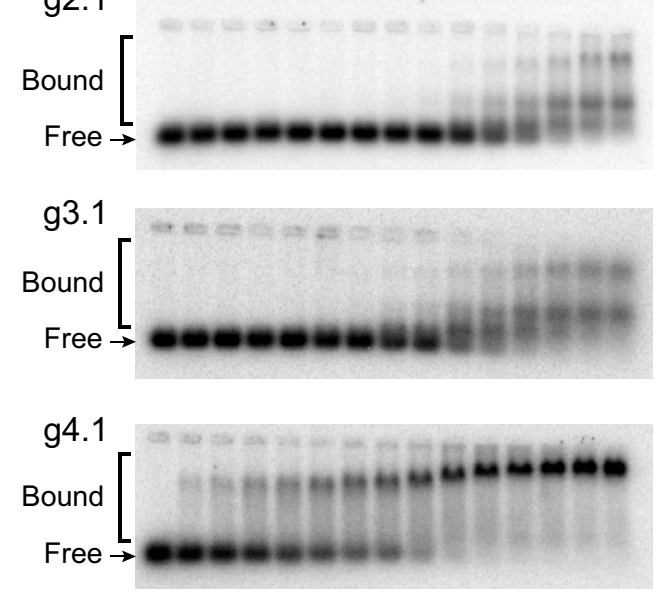

B

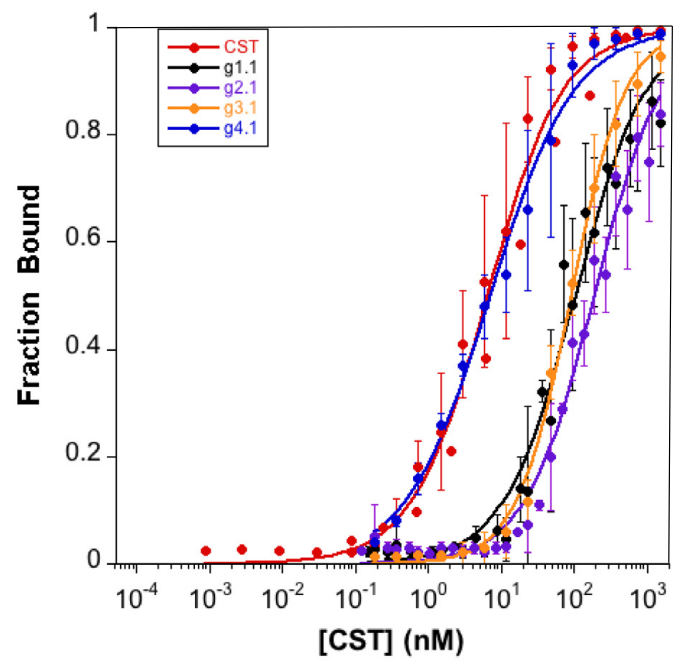

C

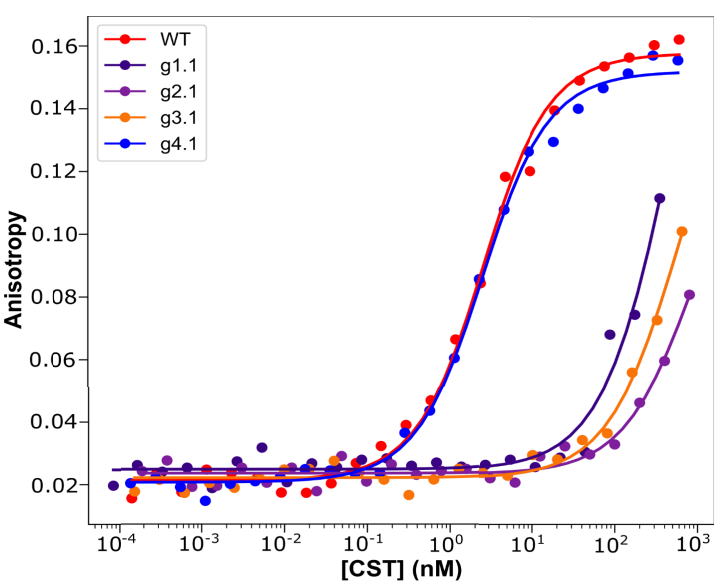

Figure 2. CST mutants show large loss of affinity for telomeric ssDNA. (A) Representative EMSA gels of 3xTEL DNA binding by WT and mutant CST proteins. (B) Quantification of fraction of DNA bound with error bars representing SD from multiple EMSA experiments (see Table 1). (C) Representative binding curves from FP assays of 3xTEL binding by WT and mutant CST proteins. Equations (1) and (2) were used for curve fitting.

Table 1. Equilibrium dissociation constants for binding of CST and telomerase to $3 \times$ TEL DNA by EMSA at $4{ }^{\circ} \mathrm{C}$ and by FP at room temperature. Each value is the mean $\pm \mathrm{SD}$ of $n$ independent experiments. Relative $K_{\mathrm{d}}$ values are normalized to WT CST. For the weak-binding CST mutants, the FP binding curves did not go to completion, so the $K_{\mathrm{d}}$ values are approximate.

\begin{tabular}{|c|c|c|c|c|c|c|c|}
\hline \multirow[b]{2}{*}{ Binders } & \multirow[b]{2}{*}{ Mutations } & \multicolumn{3}{|c|}{ EMSA } & \multicolumn{3}{|c|}{ FP } \\
\hline & & $K_{\text {d,app. }}(\mathrm{nM})$ & Relative $K_{\mathrm{d}}$ & $n$ & $K_{\text {d,app. }}(\mathrm{nM})$ & Relative $K_{\mathrm{d}}$ & $n$ \\
\hline WT CST & NA & $6.5 \pm 4.4$ & 1.0 & 9 & $2.2 \pm 0.28$ & 1.0 & 4 \\
\hline G2.1 CST & R978E, N981D, Y983A & $210 \pm 106$ & 32 & 5 & $800 \pm 220$ & 360 & 2 \\
\hline G3.1 CST & K1164E, K1167E & $97 \pm 27$ & 15 & 3 & $420 \pm 290$ & 190 & 2 \\
\hline G4.1 CST & K743E, R744E & $7.7 \pm 3.4$ & 1.1 & 3 & $2.0 \pm 0.16$ & 0.90 & 2 \\
\hline Telomerase & NA & - & - & - & $0.54 \pm 0.25$ & 0.25 & 4 \\
\hline
\end{tabular}

unchanged but the intensity of the bands decreased (Figure 3C). The decrease depended on the concentration of CST, with an $\mathrm{IC}_{50}=62 \pm 5 \mathrm{nM}$ (range of two experiments, $10 \mathrm{nM}$ DNA primer) (Figure 3D). The $\mathrm{IC}_{50}$ increased with increasing DNA primer concentration (Figure 3E, Supplementary Figure S2). The approximately linear dependence of $\mathrm{IC}_{50}$ on [DNA] is predicted from competitive binding of CST and telomerase (Supplementary Figure S3), as detailed in the next section of Results.

When the g1.1, g2.1 and g3.1 DNA-binding mutants of CST were added to the telomerase reaction, the inhibition required much higher CST concentrations (Supplementary Figure S4). In more extensive studies of the g2.1 and g3.1 mutants, weak inhibition was observed at low primer 
A

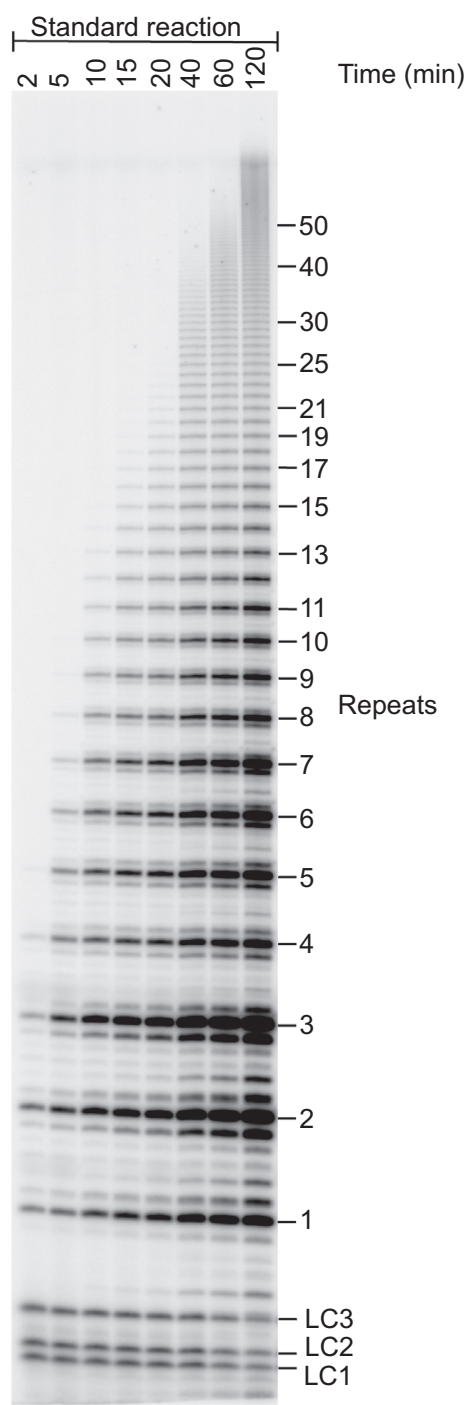

C
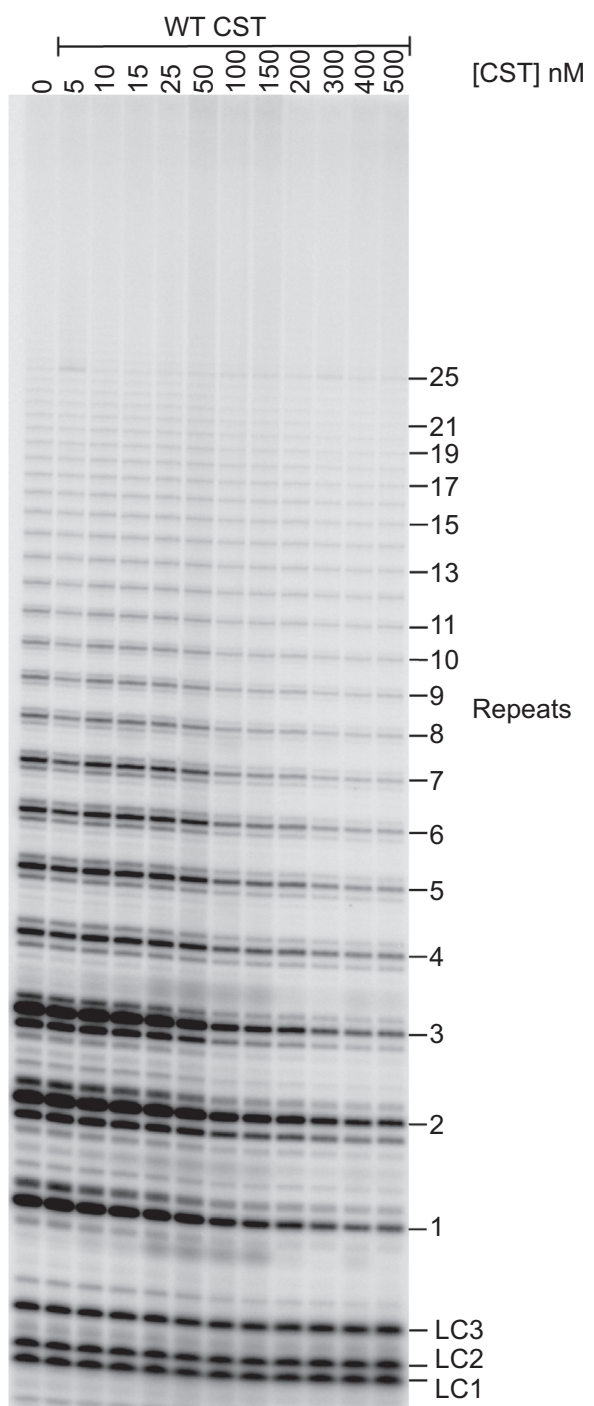

B

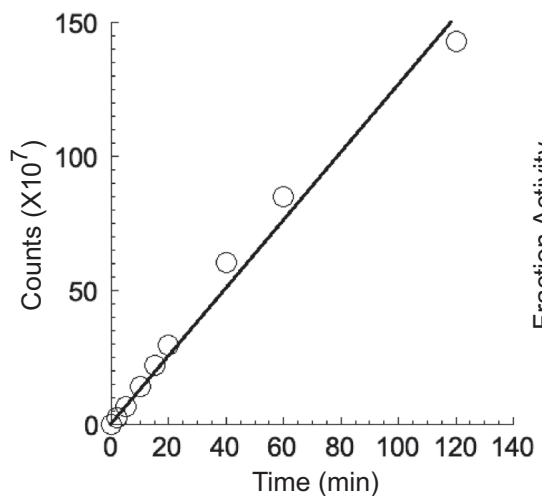

D

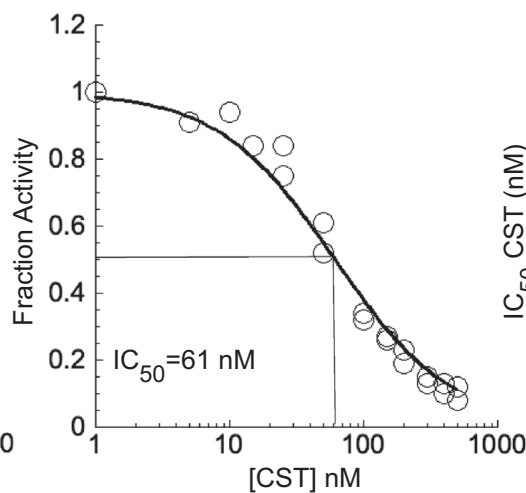

E

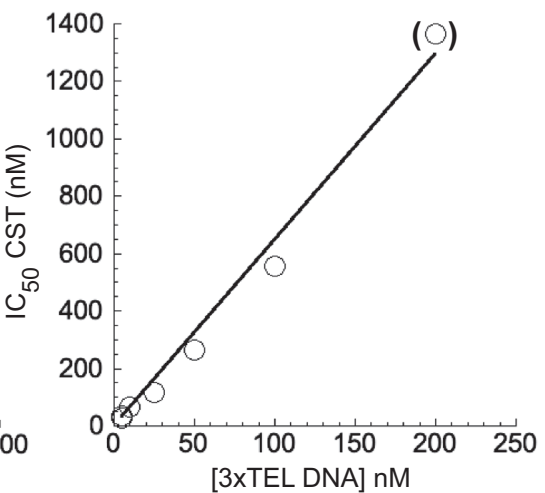

Figure 3. CST inhibits telomerase initiation. (A) Direct assay with telomerase immunopurified from HeLa cells, unlabeled $10 \mathrm{nM} 3 \mathrm{xTEL}$ DNA primer, and nucleotides including $\left[{ }^{32} \mathrm{P}\right] \mathrm{dGTP}$. LC1, LC2 and LC3 are oligonucleotides added as loading controls. (B) Radioactivity incorporated into telomerase products as a function of reaction time. (C) Telomerase assay for $1 \mathrm{~h}$ with the DNA primer pre-incubated with WT CST at the concentrations shown. (D) Counts incorporated into telomerase products normalized to the counts incorporated in the absence of CST. Data from two technical replicates included and fit to Equation (3). (E) Dependence of $\mathrm{IC}_{50}$ on the concentration of 3xTEL DNA in the reaction. Parentheses on last data point indicate that it is underdetermined, because only partial inhibition was achieved at the highest CST concentration. 
concentrations $\left(\mathrm{IC}_{50} \sim 1000 \mathrm{nM}\right)$, but with $100 \mathrm{nM}$ primer, no inhibition was observed even at 1000 nM CST (Supplementary Figures S5 and S6). Thus, inhibition of the initiation of telomerase activity by CST is dependent on CST's DNA-binding activity. The negative control g4.1 mutant showed robust inhibition, with $\mathrm{IC}_{50}$ values in the same range as WT CST (Supplementary Figure S7).

Because these inhibition reactions involve two tightbinding entities (telomerase and CST) competing for binding to the DNA primer, it is not immediately apparent how $\mathrm{IC}_{50}$ relates to $K_{\mathrm{d}}$. Thus, in the next section we utilize mathematical modeling to simulate the inhibition curves and fit them to our experimental data.

\section{Simulating telomerase inhibition by CST with the exact com- petitive binding expression}

The DNA primer sequestration model for telomerase inhibition can be considered a competitive binding equilibrium between CST and telomerase for the DNA primer (17). The schema in Figure 4A illustrates how this competition is governed by dissociation constants defined independently for CST and telomerase based on the free and bound concentrations of all species.

The concentrations of DNA, CST and telomerase relative to the magnitudes of $K_{\mathrm{d}} \mathrm{S}$ of CST and telomerase for DNA in our telomerase activity assay were such that the common simplifying assumptions to the competitive binding scenario were not applicable. We thus used the exact, assumption-free mathematical expression for competitive binding situations derived by Wang (24). This exact expression was coded into a python script to accept a series of manipulatable parameters: dissociation constants for two competing binders $\left(K_{\mathrm{d}_{\mathrm{A}}}\right.$ and $\left.K_{\mathrm{d}_{\mathrm{B}}}\right)$, concentration of ligand, initial concentration of constant binder A (telomerase), and a range of initial concentrations of titrated protein $\mathrm{B}$ (CST). The script calculated normalized fraction bound of telomerase to ligand at each input concentration of titrated CST (see Materials and Methods). The fraction bound values were then plotted against CST concentration on a logarithmic scale.

A series of test simulations were performed to verify that this exact expression behaved as expected (Supplementary Figure S8). With five different ligand concentrations $(5,25$, 50,100 and $200 \mathrm{nM}$ ) and a $2 \mathrm{nM}$ concentration of telomerase (conditions of the telomerase activity assay), we simulated the behavior of the exact expression at several ratios of dissociation constant of CST $\left(K_{\mathrm{d}_{\mathrm{B}}}\right)$ to dissociation constant of telomerase $\left(K_{\mathrm{d}_{\mathrm{A}}}\right)$. The concentration of titrated CST ranged from 0 to $1000 \mathrm{nM}$. As expected, the higher the ratio of CST-DNA $K_{\mathrm{d}_{\mathrm{B}}}$ to telomerase-DNA $K_{\mathrm{d}_{\mathrm{A}}}$ (the weaker CST's affinity for DNA relative to telomerase's affinity for DNA), the more the normalized fraction bound telomerase curves shifted to the right (more CST was required to sequester DNA from telomerase). This is apparent in Supplementary Figure S8 by comparing the family of curves in each panel.

Also as expected, increasing the initial concentration of DNA shifted the fraction bound curve to the right regardless of the ratio of CST-DNA $K_{\mathrm{d}_{\mathrm{B}}}$ to telomerase-DNA $K_{\mathrm{d}_{\mathrm{A}}}$ (compare the different curves within each panel in Supplementary Figure S8). With more DNA in solution, more CST was necessary to bind all available DNA, thereby sequestering it from telomerase. These simulations confirmed that exact expression behaved as expected. We then proceeded to fit the expression to the telomerase inhibition data to determine if the inhibition of telomerase action by CST could be successfully modelled as a competitive binding situation.

\section{Fitting experimental telomerase inhibition data to the exact competitive binding expression}

The exact competitive binding expression was then used to fit the telomerase inhibition data collected at a range of DNA concentrations to determine if the primer sequestration model accurately described telomerase inhibition by CST. Several input conditions for the expression were known in the telomerase inhibition activity assays or determined experimentally through independent methods, including initial DNA concentration, telomerase concentration, titrated CST concentrations, and CST-DNA $K_{\mathrm{d}_{\mathrm{B}}}$ (determined to be $2.2 \pm 0.28 \mathrm{nM}$ via FP, Figure $2 \mathrm{C}$ ). This left two unknown variables to be fit using our model, the telomerase-DNA $K_{\mathrm{d}_{\mathrm{A}}}$ and the active concentration of CST. For the percent of active CST, we modified the exact expression derived by Wang (24) to include a manipulatable, unitless gamma factor as a coefficient on the concentration of CST that represented the percent of active CST.

To simultaneously fit all the experimental data, we tested a set of 10000 telomerase-DNA $K_{\mathrm{DB}}$ s and gamma pairs (with limits set by reasonable physical approximations) to find the pair that minimized error between fraction bound values predicted by the exact expression and values determined in the telomerase inhibition assays. The error between predicted and experimental fraction bound was quantified by calculating the residual sum of squares (RSS) for each gamma, $K_{\mathrm{d}_{\mathrm{A}}}$ pair (see Materials and Methods).

Using this strategy, optimized values were found to be a $K_{\mathrm{d}_{\mathrm{A}}}$ of $0.324 \mathrm{nM}$ and a gamma of 0.465 . The optimized fit $K_{\mathrm{d}_{\mathrm{A}}}$ for telomerase-DNA binding was similar to that of $0.54 \pm 0.25 \mathrm{nM}$ independently determined for our telomerase enzyme by FP (Table 1 and Supplementary Figure S9). These values were then used to generate the best fit curves plotted with telomerase inhibition data (Figure 4B). Note that even at the lowest $[\mathrm{DNA}]=5 \mathrm{nM}$, the calculated $\mathrm{IC}_{50}$ is $\sim 70 \mathrm{nM} \mathrm{CST}$, far greater than the binding constant $K_{\mathrm{d}_{\mathrm{B}}}=$ $2.2 \mathrm{nM}$. The high $\mathrm{IC}_{50}$ concentration matches both experimental and fit telomerase $K_{\mathrm{d}_{\mathrm{A}}}$ values, which show telomerase has roughly a 4-7-fold higher affinity to DNA than CST.

While a $K_{\mathrm{d}_{\mathrm{A}}}$ of $0.324 \mathrm{nM}$ and a gamma of 0.465 resulted in lowest error, other pairs had similarly low error values: the RSS values for each pair are represented in a heat map (Figure 4C). This spread of low error values indicated that there is a range of pairs that similarly fit the inhibition data well. These fits show that our data convincingly support competitive primer binding as a model for telomerase-CST inhibition. 
A

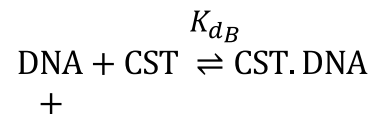

Telomerase

$K_{d_{A}}$ \

Telomerase. DNA

B

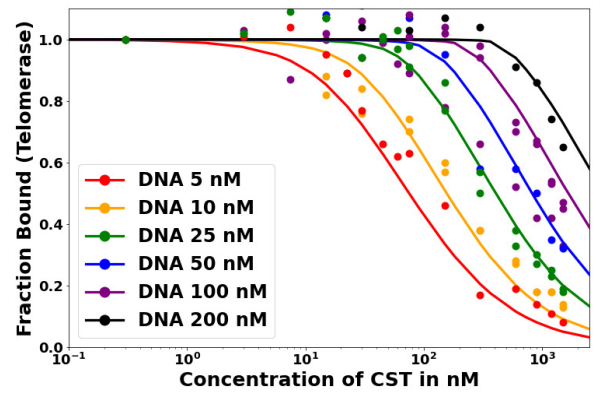

$K_{d_{B}}=\frac{[\mathrm{CST}]_{\text {free }}[\mathrm{DNA}]_{\text {free }}}{[\mathrm{CST} . \mathrm{DNA}]}$

$K_{d_{A}}=\frac{[\text { Telomerase }]_{\text {free }}[\mathrm{DNA}]_{\text {free }}}{[\text { Telomerase. DNA }]}$

C

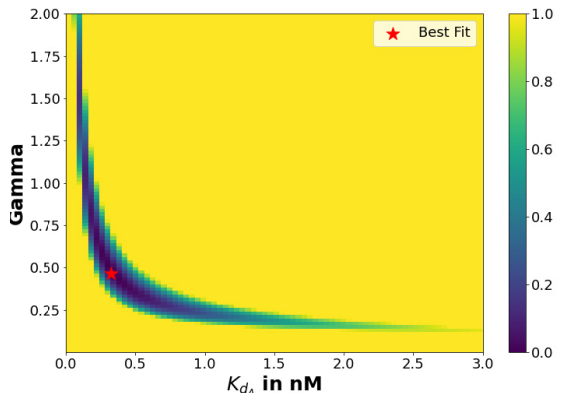

Figure 4. Fitting telomerase inhibition data. (A) Schema of competitive binding mechanism and relevant equilibrium equations. (B) Best fit telomerase inhibition curves. Telomerase inhibition assay data (points) were corrected by a factor of 3 relative to those in Supplementary Figure S2, as described in Materials and Methods. The predicted fraction bound curves were generated with optimized $K_{\mathrm{d}_{\mathrm{A}}}$ and $\gamma$ values of $0.324 \mathrm{nM}$ and 0.465 , respectively. Inhibition by WT CST. (C) Heat map of error values. Error values (residual Sum of squares, see Materials and Methods) as a function of $\gamma$ and $K_{\mathrm{d}}$ telomerase-DNA pairs with pair of best fit indicated. Value of error colored per bar on right.

\section{CST does not inhibit ongoing extension of telomeric DNA by telomerase}

As shown above, CST can compete with telomerase for binding the DNA primer and thereby inhibit initiation of G-strand synthesis. A much more powerful mode of CST inhibition might occur if it could attack and disrupt ongoing telomerase extension. However, our data suggested that CST might not affect ongoing extension. First, when WT CST was added to the telomerase reaction at $2 \mathrm{~min}$ or at $10 \mathrm{~min}$, the incorporation of radioactivity into telomerase reaction products was largely but not entirely curtailed (Figure 5A, B). Second, existing extension products continued to elongate (Figure 5C). Both observations were consistent with CST inhibiting initiation of new telomerase reactions but not affecting ongoing extension.

The ladder of extension products in telomerase reactions is generally thought to result from processive extension, because the excess of unextended primer in the reactions should act as an internal 'chase' and prevent rebinding of telomerase to previously extended products $(32,33)$. To test if the long extension products that continued to accumulate after CST addition were in fact due to processive elongation of previously initiated chains, we performed pulsechase experiments. Instead of chasing with a 3'-end-blocked DNA primer, which would prevent telomerase reinitiation but would also bind to CST, we added an excess of unlabeled dGTP along with the CST immediately after the 10 min timepoint so that all further nucleotide incorporation would be unlabeled. An example of such an experiment is shown in Figure 5D. Three observations confirmed that the pulse-chase experiment was working as expected. First, incorporation of radiolabel stopped immediately upon the addition of cold dGTP, present in 3000x excess over the ra- diolabeled dGTP (Figure 5E). Second, smaller extension products at 10 min decreased in intensity at subsequent time points, as they were chased into longer extension products (see, e.g. 7, 8 and 9 repeats). Third, longer products continued to accumulate after $10 \mathrm{~min}$. (as expected, the high [dGTP] stimulated telomerase processivity (34-36).) In conclusion, the addition of a saturating amount of WT CST clearly does not inhibit ongoing processive telomerase activity.

To control for possible nonspecific effects of adding protein to the reaction, WT CST was compared side-by-side with the g2.1 DNA-binding mutant. As shown in Figure $5 \mathrm{~F}-\mathrm{H}$, the WT and g2.1 mutant additions gave essentially identical results. Neither of them inhibited further extension of previously initiated primers (Figure $5 \mathrm{H}$ ). The stuttering banding pattern (synthesis stalls at $3 \mathrm{nt}$ as well as $6 \mathrm{nt}$ in each repeat) is caused by the higher ratio of dGTP: $\mathrm{Mg}^{++}$in this experiment ( $5 \mathrm{mM}$ dGTP: $1 \mathrm{mM} \mathrm{MgCl}_{2}$ ). Thus, even under conditions where telomerase extension is suboptimal, the CST has no detectable ability to inhibit ongoing telomerase extension. Pulse-chase reactions with $1 \mathrm{mM}$ dGTP: $1 \mathrm{mM} \mathrm{MgCl}$, which do not give the stuttering pattern, again showed no difference between WT and g2.1 CST (Figure 6C).

\section{CST inhibits telomerase extension independent of bound pol $\alpha$-primase}

Pol $\alpha$-primase copurified with the CST purified from HEK$293 \mathrm{~T}$ cells. The exception was the g1.1 mutant, which lost pol $\alpha$-primase association (Figure 1C, Supplementary Figure S1). Because the g1.1 mutant inhibited telomerase activity only at high concentrations, similar to g2.1 and g3.1 which retain pol $\alpha$-primase, it appeared that pol $\alpha$ - 
A

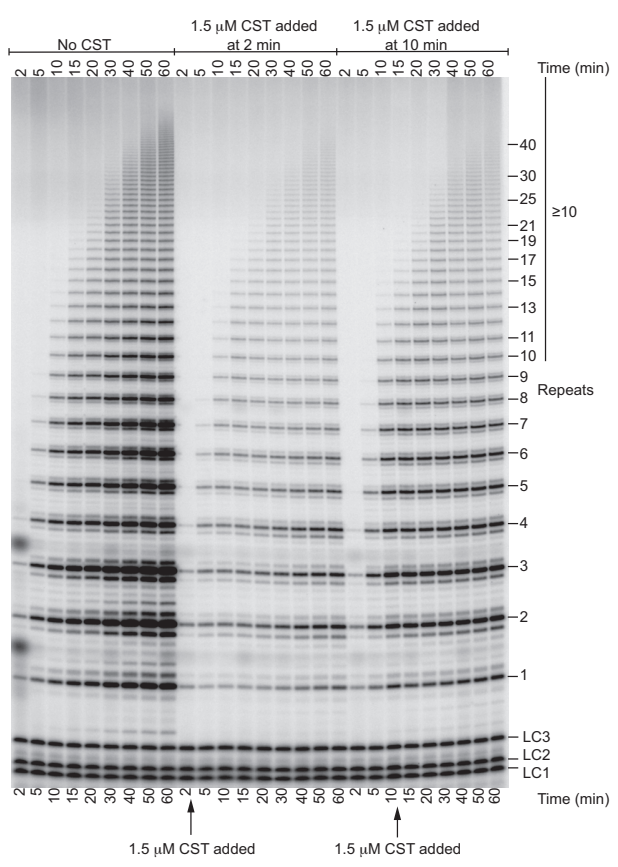

B

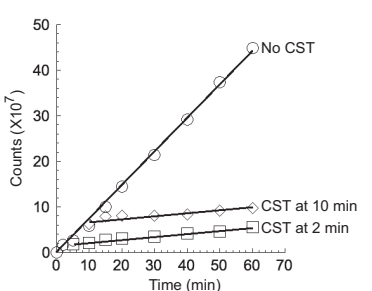

C

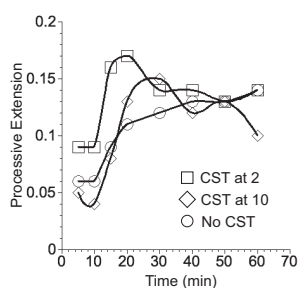

D

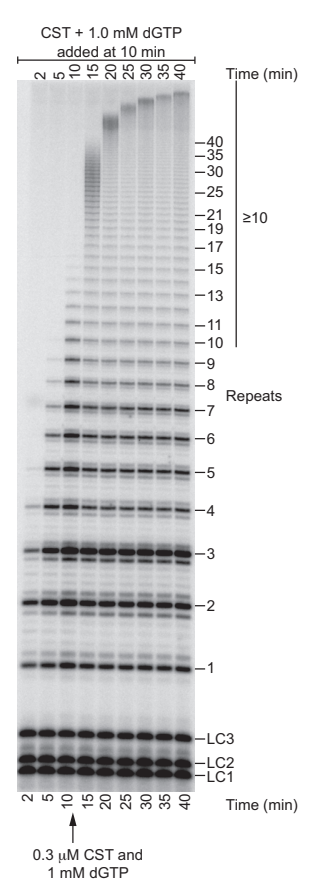

E

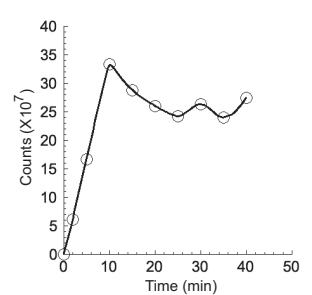

$\mathbf{F}$

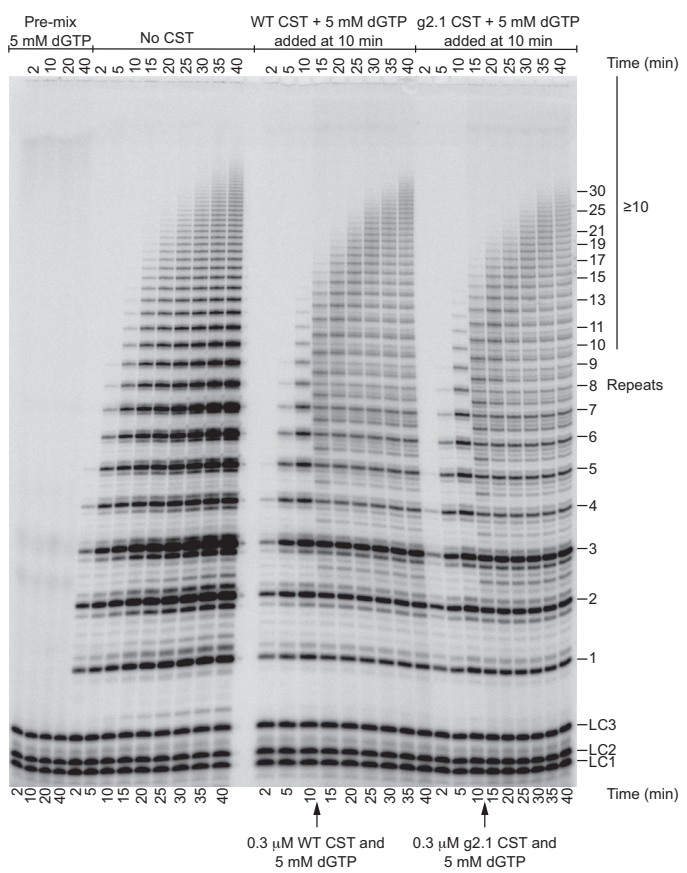

G

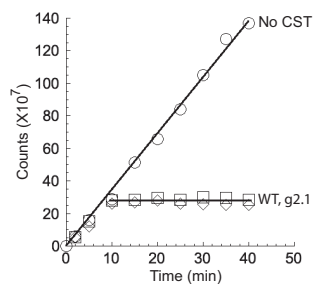

H

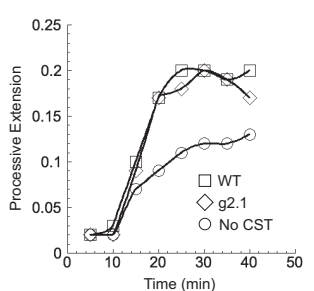

Figure 5. Pulse-chase experiments show that CST does not disrupt ongoing telomerase extension. (A) Direct telomerase assay with WT CST added after 2 or 10 min of reaction. All three time courses had the same $\left.{ }^{32} \mathrm{P}\right] \mathrm{GTP}$, so intensity differences are due to inhibition by added CST. (B) Radioactivity incorporated into telomerase products as a function of reaction time. (C) Long extension products ( $\geq 10$ repeats, see bar to right of panel A) as a fraction of total incorporation. Data points are connected to aid visualization. (D) Pulse-chase experiment in which excess unlabeled dGTP was added along with CST to restrict observed products to previously initiated chains. High [dGTP] drives high processivity. (E) Radioactivity incorporated into telomerase reaction products stops increasing when unlabeled dGTP is added at $10 \mathrm{~min}$. Data points are connected to aid visualization. (F) WT CST and DNA-binding mutant g2.1 CST are equally unable to disrupt ongoing telomerase extension under conditions that cause telomerase stuttering. Pulse-chase experiments with 5 $\mathrm{mM}$ unlabeled dGTP instead of the standard $1 \mathrm{mM}$ dGTP. The pre-mix control (first four lanes) shows that the addition of the unlabeled dGTP was sufficient to prevent further labeling of products. (G) Radioactivity incorporated into telomerase products in the experiment of panel (F). Symbols for WT and g2.1 CST overlap. $(\mathbf{H})$ Long extension products as a fraction of total incorporation in the experiment of panel (F). Data points are connected to aid visualization. The values with no CST addition are lower because small products continue to be initiated, increasing the total counts relative to the long extension products.

primase was not responsible for the inhibition seen with CST.

We sought an independent test of this hypothesis. We found that immunopurification of the CST under higher salt conditions, $300 \mathrm{mM} \mathrm{NaCl}$ instead of our standard 150 $\mathrm{mM} \mathrm{NaCl}$, released the pol $\alpha$-primase without otherwise affecting the purification of CST (Figure 6A). The 150 and $300 \mathrm{mM} \mathrm{NaCl}$ preparations of CST were compared in a pulse-chase experiment, and they were found to be equivalent: they both prevented further initiation of telomerase, and they both allowed processive extension of pre-initiated chains (Figure 6B-E). Thus, pol $\alpha$-primase does not appear to be responsible for or to affect CST inhibition of telomerase.

\section{DISCUSSION}

The switch from telomeric G-strand synthesis by telomerase to $\mathrm{C}$-strand synthesis by pol $\alpha$-primase is a critical step in telomere replication. The CST complex is key in orchestrating this switch, but its mechanism of action is incompletely known. Here, we extend the understanding of CST inhibition of telomerase extension in three ways. First, we validate DNA-binding mutants of CST and show that they no longer inhibit telomerase initiation, providing strong additional support for the primer sequestration model. Second, we develop an exact model for CST inhibition of telomerase, which reconciles the $K_{\mathrm{d}}$ values for telomerase and CST binding to the DNA primer with the much higher $\mathrm{IC}_{50}$ values obtained from the inhibition curves. Finally, we show 
A

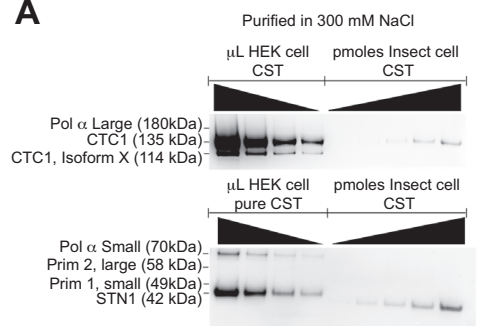

B

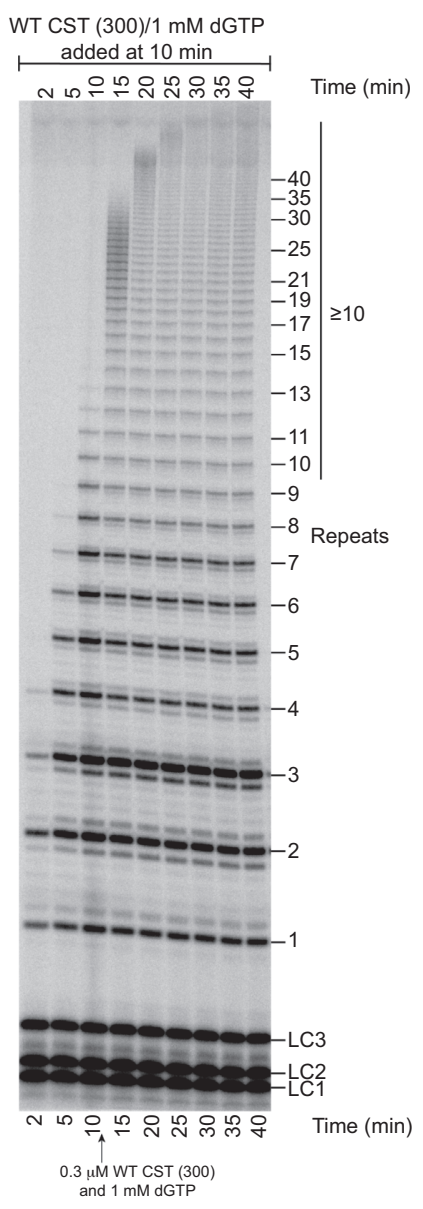

D

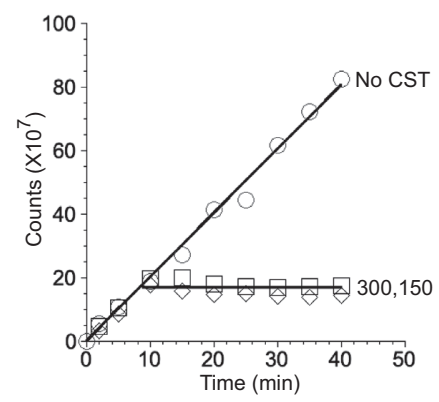

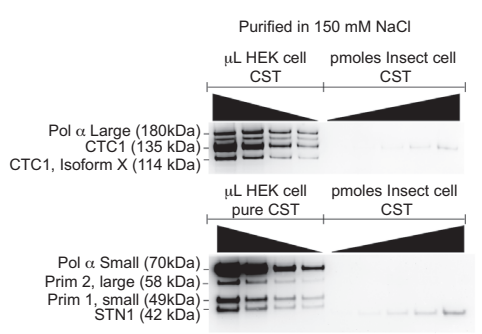

C

WT CST (150)/1 mM dGTP g2.1 CST/1 mM dGTP

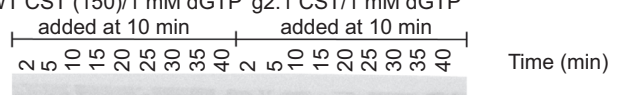

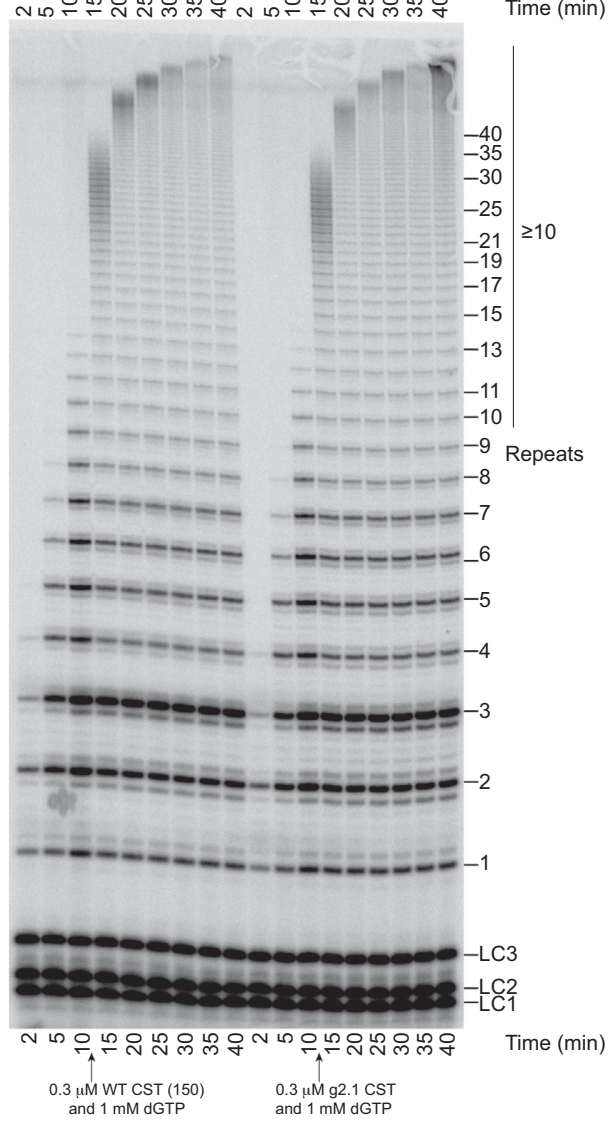

E

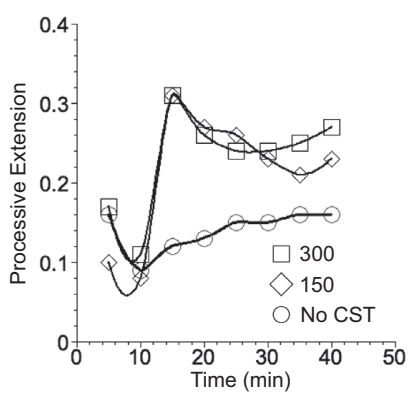

Figure 6. CST inhibits telomerase extension independent of bound pol $\alpha$-primase. (A) Western blot analysis of WT CST purified in standard $150 \mathrm{mM} \mathrm{NaCl}$ or in $300 \mathrm{mM} \mathrm{NaCl}$. Top blots probed with antibodies to CTC1 and to the large subunit of pol $\alpha$. Bottom blots probed with antibodies to STN1, the small subunit of pol $\alpha$, and the two subunits of primase (Prim 1 and 2). Wedges indicate successive two-fold dilutions of protein. (B) Pulse-chase experiment with WT CST purified in $300 \mathrm{mM} \mathrm{NaCl}$. (C) Pulse-chase experiments with WT CST purified in $150 \mathrm{mM} \mathrm{NaCl}$ (left lanes) and with g2.1 mutant CST purified in $150 \mathrm{mM} \mathrm{NaCl}$ (right lanes). (D) Radioactivity incorporated into telomerase products as a function of reaction time without chase (No CST) or in the pulse-chase experiments of panel (B) and left half of (C) (300 and 150, respectively). (E) Long extension products ( $\geq 10$ repeats) as a fraction of total incorporation in the same pulse-chase experiments. Data points are connected to aid visualization. 
that CST does not have the intrinsic ability to evict telomerase from telomeric DNA during a primer-extension reaction.

\section{An exact model for CST inhibition of telomerase}

While CST has previously been suggested to inhibit telomerase through the direct and competitive binding of the telomeric ssDNA ligand, more sophisticated actions by CST could not be ruled out (17). We have determined the extent to which a competitive binding model evaluated with an exact treatment of coupled equilibrium (24) fits the experimental telomerase inhibition profiles. The strength of this approach is that it requires no a priori assumptions about relative dissociation constants or limiting values to predict the equilibrium concentrations of all species. This model, however, treats the telomerase-DNA interaction as a straightforward binding interaction, a potentially deleterious oversimplification of the complex enzymatic machinery. Phenomenon such as partial dissociations, multiple binding modes, processivity and change in affinity for an active telomerase are not expected to be accurately encapsulated by a single binding constant. Thus, it is somewhat surprising that this model represents the inhibition data quite well. Furthermore, the fitted value for telomerase-DNA binding affinity (Figure 4B) matches within error to the value obtained independently in a binding experiment (Table 1). This binding affinity $(0.52 \pm 0.25 \mathrm{nM})$ is similar to other values reported in the literature measured with alternate methods of $0.5 \pm 0.3 \mathrm{nM}(37)$ and $3.3 \pm 0.5 \mathrm{nM}$ (38). The high congruence of the model with the data, as well as the consistent telomerase-DNA affinity values obtained, strongly support that the core action of telomerase inhibition by CST is through the mechanism of competitive binding for ligand. This mechanism suggests the possibility that regulation of telomerase action could be achieved by controlling the CST concentration at the telomere.

\section{How does CST terminate telomerase extension?}

Telomerase is unable to extend ssDNA primers in the presence of a saturating amount of CST. This activity can be explained by a simple primer sequestration model (17). That is, CST binding to the primer sequesters it and precludes telomerase binding. Our detailed quantitative analysis with DNA-binding mutants of CST provides strong confirmation of the primer sequestration model with no need to invoke additional CST activities.

How effective might CST inhibition of initiation be for termination of telomerase in vivo? During homeostatic telomere length maintenance, human telomerase is thought to extend most telomeres in each cell cycle, adding about 60 nt to each telomere processively after a single binding event (39). The intrinsic activities of CST determined by in vitro analysis are in complete accord with such a model. Given its ability to sequester the primer and block reinitiation, CST could help restrict telomerase extension to a single round. Because it is unable to evict telomerase from elongating DNA, it would not interfere with the single round of extension.

On the other hand, when telomeres are undergoing net elongation, Zhao et al. (39) report that multiple telomerase molecules act at each telomere; i.e., extension is distributive rather than processive. Perhaps under these conditions there is insufficient CST available at the telomere to prevent telomerase reinitiation.

How does the switch from telomerase synthesis of the telomeric G-strand to pol $\alpha$-primase synthesis of the Cstrand occur? Because we find no evidence that CST can evict telomerase from elongating DNA under multiple in vitro conditions, the switch from G-strand to C-strand synthesis may be passive rather than active. Given its modest processivity, telomerase will terminate spontaneously after adding a limited number of telomeric repeats, measured as $\sim 4$ repeats in vitro (40) and $\sim 10$ repeats in cells (39). Inhibition occurs when CST then binds the newly extended DNA and prevents telomerase reinitiation. At the same time, CST brings in pol $\alpha$-primase to initiate $\mathrm{C}$-strand synthesis.

The relative activity of the CST heterotrimeric 'monomer' and the 2-megadalton decameric supercomplex in inhibiting telomerase is not addressed by our study. We think that the results presented here pertain to the CST monomer. The HEK cell-based CST purification gives low concentrations of CST, and under these conditions we have not observed the decameric supercomplex (although our evidence suggests that it is present in cells (22)). Given that the decamer is poised to bind ssDNA more aggressively than the monomer (22), we might expect it to have greater telomerase-inhibiting activity than the monomer.

Because the POT1-TPP1 telomere-binding proteins stabilize the association of telomerase with telomeric DNA during active extension $(41,42)$, we expect that CST would be even less likely to evict telomerase engaged with POT1TPP1. However, we have not tested this hypothesis. The experimental approaches and computational analysis developed herein provide the groundwork for future studies to test the activity of shelterin proteins and other telomere components on the switch from telomeric G-strand to Cstrand synthesis.

\section{DATA AVAILABILITY}

CST_Inhibits_Telomerase is available in the GitHub repository (https://github.com/mtcarilli/ CST_Inhibits_Telomerase).

\section{SUPPLEMENTARY DATA}

Supplementary Data are available at NAR Online.

\section{ACKNOWLEDGEMENTS}

We thank D. Herschlag (Stanford U.) and J. Lingner (EPFL, Lausanne) for valuable discussions. We thank T. Nahreini for her excellent management of the Biochemistry Cell Culture Facility, CU Boulder. T.R.C. is an investigator of the Howard Hughes Medical Institute.

\section{FUNDING}

National Institutes of Health [R00 GM131023 to C.L., R01 GM139274 to D.S.W.]; National Science Foundation [MCB 
1716425 to D.S.W.]; M.T.C. was supported by the Biological Sciences Initiative funded by the University of Colorado Boulder; Howard Hughes Medical Institute through the Science Education Program. Funding for open access charge: Howard Hughes Medical Institute and the University of Colorado Boulder Open Access Fund.

Conflict of interest statement. T.R.C. is a scientific advisor for Storm Therapeutics and Eikon Therapeutics.

\section{REFERENCES}

1. Blackburn,E.H. and Greider,C.W. (1989) A telomeric sequence in the RNA of Tetrahymena telomerase required for telomere repeat synthesis. Nature, 337, 331-337.

2. Lingner,J., Hughes,T.R., Shevchenko,A., Mann,M., Lundblad,V. and Cech,T.R. (1997) Reverse transcriptase motifs in the catalytic subunit of telomerase. Science, 276, 561-567.

3. Egan,E.D. and Collins,K. (2012) Biogenesis of telomerase ribonucleoproteins. $R N A, \mathbf{1 8}, 1747-1759$.

4. Lemieux,B, Laterreur,N, Perederina,A, Noël,J.-F., Dubois,M.L., Kraslinikov,A.S. and Wellinger,R.J. (2016) Active yeast telomerase shares subunits with ribonucleoproteins RNase P and RNase MRP. Cell, 165, 1171-1181.

5. Roake,C.M. and Artandi,S.E. (2020) Regulation of human telomerase in homeostasis and disease. Nat. Rev. Mol. Cell Biol., 21, 384-397.

6. Schmidt,J.C., Zaug,A.J. and Cech,T.R. (2016) Live cell imaging reveals the dynamics of telomerase recruitment to telomeres. Cell, 166, 1188-1197.

7. Jiang,J., Chan,H., Cash,D.D., Miracco,E.J., Ogoarzalek Loo,R.R., Upton,H.E., Cascio,D., O'Brien Johnson,R., Collins,K., Loo,J.A. et al. (2015) Structure of Tetrahymena telomerase reveals previously unknown subunits, functions, and interactions. Science, 350, aab4070.

8. Ghanim,G.E., Fountain,A.J., van Roon,A.-M.M., Rangan,R., Das, R., Collins, K. and Nguyen,T.H.D. (2021) Structure of human telomerase holoenzyme with bound telomeric DNA. Nature, 593, 449-453.

9. Fan,X. and Price,C.M. (1997) Coordinate regulation of G- and C strand length during new telomere synthesis. Mol. Biol. Cell, 8 , $2145-2155$.

10. Diede,S.J. and Gottschling,D.E. (1999). Telomerase-mediated telomere addition in vivo requires DNA primase and DNA polymerase $\alpha$ and $\delta$. Cell, 99, 723-733.

11. Chandra,A., Hughes,T.R., Nugent,C.I. and Lundblad,V. (2001) Cdc13 both positively and negatively regulates telomere replication. Genes Dev., 15, 404-414.

12. Wang,F., Stewart,J.A., Kasbek,C., Zhao,Y., Wright,W.E. and Price,C.M. (2012) Human CST has independent function during telomere duplex replication and C-Strand Fill-in. Cell Rep., 2 , 1096-1103.

13. Huang,C., Dai,X. and Chai,W. (2012) Human Stn1 protects telomere integrity by promoting efficient lagging-strand synthesis at telomeres and mediating C-strand fill-in. Cell Res., 22, 1681-1695.

14. Feng,X., Hsu,S.J., Kasbek,C., Chaiken,M. and Price,C.M. (2017) CTC1-mediated C-strand fill-in is an essential step in telomere length maintenance. Nucleic Acids Res., 45, 4281-4293.

15. Miyake,Y., Nakamura,M., Nabetani,A., Shimamura,S., Tamura,M., Yonehara,S., Saito,M. and Ishikawa,F. (2009) RPA-like mammalian Ctc1-Stn1-Ten1 complex binds to single-stranded DNA and protects telomeres independently of Pot1 pathway. Mol. Cell, 36, 193-206.

16. Surovtseva,Y.V., Churikov,D., Boltz,K.A., Song,X., Lamb,J.C., Warrington, R., Leehy,K., Heackock,M., Price,C.M. and Shippen,D.E. (2009) Conserved telomere maintenance component 1 interacts with STN1 and maintains chromosome ends in higher eukaryotes. Mol. Cell, 36, 207-218.

17. Chen,L.Y., Redon,S. and Lingner,J. (2012) The human CST complex is a terminator of telomerase activity. Nature, 488, 540-544.

18. Hom,R.A. and Wuttke,D.S. (2017) Human CST prefers G-rich but not necessarily telomeric sequences. Biochemistry, 56, 4210-4218.

19. Casteel,D.E., Zhuang,S., Zeng,Y., Perrino,F.W., Boss,G.R., Goulian,M. and Pilz,R.B. (2009) A DNA polymerase- $\alpha$-primase cofactor with homology to replication protein A-32 regulates DNA replication in mammalian cells. J. Biol. Chem., 284, 5807-5818.

20. Bryan,C., Rice,C., Harkisheimer,M., Schultz,D.C. and Skordalakes,E. (2013) Structure of the human telomeric Stn1-Ten1 capping complex. PLoS One, 8, e66756.

21. Shastrula,P.K., Rice,C.T., Wang,Z., Lieberman,P.M. and Skordalakes,E. (2018) Structural and functional analysis of an OB-fold human Ctcl implicated in telomere maintenance and bone marrow syndromes. Nucleic Acids Res., 46, 972-984.

22. Lim,C.J., Barbour,A.T., Zaug,A.J., Goodrich,K.J., McKay,A.E., Wuttke,D.S. and Cech,T.R. (2020) The structure of human CST reveals a decameric assembly bound to telomeric DNA. Science, $\mathbf{3 6 8}$, 1081-1085.

23. Cristofari,G. and Lingner,J. (2006) Telomere length homeostasis requires that telomerase levels are limiting. EMBO J., 25, 565-574.

24. Wang,Z.X. (1995) An Exact mathematical expression for describing competitive binding of two different ligands to a protein. FEBS Lett., 360, $111-114$.

25. Hunter,J.D. (2007) Matplotlib: a 2D graphics environment. Comput. Sci. Eng., 9, 90-95.

26. Goulian,M., Heard,C.J. and Grimm,S.L. (1990) Purification and properties of an accessory protein for DNA polymerase $\alpha /$ primase. $J$. Biol. Chem., 265, 13221-13230.

27. Goulain,M. and Heard,C.J. (1990) The mechanism of action of an accessory protein for DNA polymerase $\alpha /$ primase. J. Biol. Chem., 265, 13231-13239.

28. Chen,L.Y., Majerská,J. and Lingner,J. (2013) Molecular basis of telomere syndrome caused by CTC1 mutations. Genes Dev., 27, 2099-2108.

29. Kelich,J.M., Papaioannou,H. and Skordalakes,E. (2021) Pol $\alpha$-primase dependent nuclear localization of mammalian CST complex. Commun. Biol., 4, 349-359.

30. Feng,X., Hsu,S.J., Bhattacharjee,A, Wang,Y., Diao,J. and Price,C.M. (2018) CTC1-STN1 terminates telomerase while STN1-TEN1 enables $\mathrm{C}$-strand synthesis during telomere replication in colon cancer cells. Nat. Commun., 9, 2827-2838.

31. Gu,P., Jia,S., Takasugi,T., Smith,E., Nandakumar,J., Hendrickson,E. and Chang,S. (2018) CTC1-STN1 coordinates G- and C- strand synthesis to regulate telomere length. Aging Cell, 17, e12783.

32. Bryan,T.M., Goodrich,K.J. and Cech,T.R. (2000) A mutant of Tetrahymena telomerase reverse transcriptase with increased processivity. J. Biol. Chem., 275, 24199-24207.

33. Chen,J.-L. and Greider,C.W. (2003) Template boundary definition in mammalian telomerase. Genes Dev., 17, 2747-2752.

34. Hammond,P.W. and Cech,T.R. (1997) dGTP-dependent processivity and possible template switching of Euplotes telomerase. Nucleic Acids Res., 25, 3698-3704.

35. Maine,I.P., Chen,S.F. and Windle,B. (1999) Effect of dGTP concentration of human and $\mathrm{CHO}$ telomerase. Biochemistry, 38, $15325-15332$.

36. Hardy,C.D., Schultz,C.S. and Collins,K. (2001) Requirements for the dGTP-dependent repeat addition processivity of recombinant Tetrahymena telomerase. J. Biol. Chem., 276, 4863-4871.

37. Jurczyluk,J., Nouwens,A.S., Holien,J.K., Adams, T.E., Lovrecz,G.O., Parker,M.W., Cohen,S.B. and Bryan,T.M. (2011) Direct involvement of the TEN domain at the active site of human telomerase. Nucleic Acids Res., 39, 1774-1788.

38. Tomlinson,C.G., Moye,A.L., Holien,J.K., Parker,M.W., Cohen,S.B. and Bryan,T.M. (2015) Two-step mechanism involving active-site conformational changes regulates human telomerase DNA binding. Biochem J., 465, 347-357.

39. Zhao,Y., Abreu,E., Kim,J., Stadler,G., Eskiocak,U., Terns,M.P., Terns,R.M., Shay,J.W. and Wright,W.E. (2011) Processive and distributive extension of human telomeres by telomerase under homeostatic and nonequilibrium conditions. Mol. Cell, 42, 297-307.

40. Wang,F., Podell,E.R., Zaug,A.J., Yang,Y., Baciu,P., Cech,T.R. and Lei,M. (2007) The POT1-TPP1 telomere complex is a telomerase processivity factor. Nature, 445, 506-510.

41. Latrick,C.M and Cech,T.R. (2010) POT1-TPP1 enhances telomerase processivity by slowing primer dissociation and aiding translocation. EMBO J., 29, 924-933.

42. Dalby,A.B., Hofr,C. and Cech,T.R. (2015) Contributions of the TEL-patch amino acid cluster on TPP1 to telomeric DNA synthesis by human telomerase. J. Mol. Biol., 427, 1291-1303. 